\title{
World Psychiatric Association and the College
}

\author{
John Cox
}

Secretary General, World Psychiatric Association and Immediate Past President of the Royal College of Psychiatrists; Keele University Medical School - Harplands Campus, Hilton Road, Stoke on Trent, UK

greatly welcome this opportunity to contribute to the first edition of International Psychiatry and to wish it well on its maiden voyage; the aim of this contribution is to outline those structures and objectives of the World Psychiatric Association (WPA) that are relevant to members of the Royal College of Psychiatrists.

The WPA is an organisation of psychiatric societies; its objective is to advance psychiatric and mental health care, education and public policy across the world. The Royal C ollege of Psychiatrists is one of 122 member societies in 105 countries and has contributed actively since the first World Congress, held in Paris in 1950. Sir Martin Roth and Linford Rees, for example, were both influential at this Congress and Dennis Leigh was the widely respected second Secretary General - renow ned for his enthusiastic commitment to links with member societies.

My election last year as Secretary General at the G eneral Assembly in Japan catapulted me into the heart of WPA planning, with the expectation that British psychiatrists will continue to work within this value-laden global organisation. Several distinguished members and honorary fellows are making huge contributions to its work. Sir D avid Goldberg was awarded the Jean D elay Prize, Professor Eugene Paykel was the zonal representative for Western Europe (now succeeded by Brian Martindale) and several past Presidents of the W PA - Felice Lieh Mak, N orman Sartorius and Juan Lopez Ibor - are honorary fellows of the College in recognition, inter alia, of their services to world psychiatry.

At present, the renewed internationalism of the College and the establishment of the International Board led by $\mathrm{H}$ amid $\mathrm{G}$ hodse will ensure that the College continues to contribute actively to the W PA and to share its institutional strength with others. The WHO and W PA work closely to gether and represent the potential clout of governments and the collective wisdom of clinicians to improve the care of patients with mental disorder. Recently, new joint task forces on vario us mental disorders have been established and, for example, member societies are producing updated information for the next edition of the World Atlas, which so starkly illustrated the inequities in the provision of mental health services across the world.

The W PA has been likened to a family and certainly there is no shortage of squabbles; yet I have been impressed by the determination of its leaders and the evident commitment of its members, often isolated and lacking institutional strength, to realise the vision that the world's psychiatrists can and should speak out and help each other to advance the knowledge base of our subject.

\section{WPA: purpose and structure}

The purposes of the W PA include:

O advancing knowledge and skills in the treatment of mental disorder

o promotingmental health

o preserving the human rights of those with mental illness

o establishing the core roles and responsibilities of psychiatrists.

The General Assembly is the governing body and meets every three years. It is democratic in its structures, which are carefully described in the $M$ anual of Procedures. Major decisions are taken by ballot and the voting system ensures that no single member society, however large, can dominate decision-making. A representative of each member society (usually its president) has to be present to vote. The Executive Committee (Table 1) has the responsibility of governing the W PA between assemblies. The term of office of Executive Committee members is six years (i.e. two World Congresses). Executive Committee members hold honorary appointments.

There are five regions and 18 zones, each with a zonal representative elected by the General Assembly for a three-year term, with an expected further term (Table 2). The College is in the Western Europe Zone.

The meeting in June with W HO , UEMS and AEP representatives in Vienna could further advance thinking about the responsibilities of psychiatrists and how European psychiatry can make a greater impact. The College as a member society through its enhanced international groups can assist to strengthen these W PA regional initiatives.

\section{Science}

The scientific arm of the WPA is undoubtedly the 55 sections. Many C ollege members working in the UK are active in this work as office bearers, including Chris Thompson, Cornelius Katona, Mohammed Abou-Saleh, D avid N utt, N ick Bouras, Rachel Jenkins, Hugh Freeman,

Table 1. The WPA Executive Committee, 2003

Office Current holder

\section{President}

President elect

Secretary General

Secretary for Finance

Secretary for M eetings

Secretary for Education

Secretary for Publications

Secretary for Sections
Ahmed Okasha (Egypt)

Juan E. Mezzich (USA)

John Cox (UK)

Sam Tyano (Israel)

Pedro Ruiz (USA)

Roger Montenegro (Argentina)

Mario Maj (Italy)

George Christodoulou (Greece)

WPA news also features in 'News and notes', this issue, pp. 21-23

The WPA is an organisation of psychiatric societies; its objec-

tive is to advance psychiatric and mental health care, education and public policy across the world.

The Royal College

of Psychiatrists is one of 122

member societies

in 105 countries 
Peter Tyrer and Linda Gask. lan Brockington was the first chair of the Women's Mental H ealth Section.

Many sections, but not all, are active and all have the problem of matching aspiration with the minimal resources available. However, they are the backbone of the World Congresses and members of the College who wish to contribute to world psychiatry and to meet with colleagues

Table 2. The WPA's zones and representatives, 2003

\begin{tabular}{clll}
\hline Zone & Geographical region & Current representatives & Representative's country \\
\hline 1 & Canada & Werner Pankratz & Canada \\
2 & United States of America & Allan Tasman & United State of America \\
3 & Mexico, Central America & & \\
& and the Caribbean & Enrique Camarena & M exico \\
4 & Northern South America & Edgard Belford & Venezuela \\
5 & Southern South America & Miguel R. Jorge & Brazil \\
6 & Western Europe & Brian Martindale & United Kingdom \\
7 & Northern Europe & Marianne Kastrup & Denmark \\
8 & Southern Europe & Levent Luey & Turkey \\
9 & Central Europe & Petr Smolik & Czech Republic \\
10 & Eastern Europe & Valery Krasnow & Russia \\
11 & Northern Africa & Tarek Okasha & Egypt \\
12 & Middle East & Fuad Antun & Lebanon \\
13 & Western and Central Africa & Michael Olatawura & Nigeria \\
14 & Southern and Eastern Africa & Fred Kigozi & Uganda \\
15 & Western and Central Asia & Haroon Rashid Chaudhry & Pakistan \\
16 & Southern Asia & Parameshvara Deva & Malaysia \\
17 & Eastern Asia & Jiro Suzuki & Japan \\
18 & Australasia and South Pacific & Graham M ellsop & New Zealand \\
\hline
\end{tabular}

The website of the WPA is www.wpanet.org

from large and small societies will find these scientific meetings stimulating and leading to collaborative research, as well as new friends.

\section{Publications and communication}

These are impressive. Mario $\mathrm{Maj}$, from $\mathrm{N}$ aples, the Secretary for Publications, has established the new W PA journal World Psychiatry, which is distributed free to 22000 psychiatrists.

The W PA's book series have also been well received - 'Evidence and Experience in Psychiatry', 'Images in Psychiatry' and 'Anthologies in Psychiatry'.

\section{How is the WPA financed?}

Financial support comes from membership fees (which are proportional to the size of the society and to its category of economic standing) as well as W PA congresses and other scientific meetings, external grants, publications and corporate supporters from industry.

As the College knows, a joint regional meeting with the W PA carries a financial risk but a co-sponso red meeting less so. The rewards, however, in terms of international exchange, heightened profile and closer links between member societies can be substantial. The Latin American countries, for example, have grouped themselves together into a Latin American Psychiatric Society and attract large numbers of participants at meetings as well as substantial sponsorship.

\section{WPA on the web}

This site (www.wpanet.org) is very active and visitors can obtain all issues of W PA N ews, World Psychiatry, section newsletters, the Madrid Declaration as well as the new Electronic Bulletin.

\section{Ethics}

Promotion of the highest ethical standards in care, teaching and research is a constitutional commitment. The W PA ethical guidelines for psychiatric practice were revised at the General Assembly in Japan and provide the ethical framew ork within which the Review Committee of the W PA investigates allegations of political abuse or other unethical practice. A member society is required to cooperate with the Review Committee. The W PA has a powerful sanction though the General Assembly to suspend membership of a society if it concludes that it is in breech of the Madrid D eclaration.

The Review Committee is meeting with the Chinese Society of Psychiatrists and the Executive of the W PA in San Francisco to clarify some persisting ambiguities in the Chinese Society of Psychiatrists' response to the Review Committee. Plans for an educational symposium are in hand and the President of the W PA (Professor Ahmed $O$ kasha) is meeting with the new government officials in Beijing. What is lacking at present is the possibility to meet with the patients and the clinicians face to face where there has been an allegation of political abuse. The College voice has been heard effectively through its President, and undoubtedly its influence has been helpful in seeking answers to the allegations. I am a new member of the Review Committee; Bob Daly was a previous consultant and Mike Shooter was able to meet the Review Committee in London. The Chinese Society of Psychiatrists has been working with the W PA on these issues but it remains possible that abuse of psychiatry at an individual or institutional level may be occurring in the hospitals that are not in the public health system.

\section{Education}

I would commend the following reports to members of the College, which can be downloaded from the website.

o Core Training Curriculum for Psychiatry

- Core Curriculum in Psychiatry for M edical Students

o W PA International G uidelines for D iagnostic Assessment (IGDA) (published as a supplement to the British Journal of Psychiatry in May 2003);

o Fighting Stigma Due to Schizophrenia.

\section{Postlude}

I hope this article will have reminded members about what is happening in the WPA and will have encouraged readers to get involved in its work.

My specific responsibilities are to ensure that the secretariat works efficiently, as well as making wider contributions to the W PA. Some may be surprised that an administrator and two and a half secretaries working from 
a minute office in $\mathrm{N}$ ew York underpin the organisation. $\mathrm{A}$ decision has been made, however, by the General Assembly to establish a permanent secretariat by 2005 rather than a secretariat that rotates with the place of work of the Secretary G eneral, so I am experimenting already with a new system of w orking. A part-time W PA secretary at Keele has helped me to keep my finger on the pulse and the College gift of a laptop when I demitted office was shrewd forward thinking!

The College has the notification and timeline of the bidding process for the permanent secretariat and the criteria against which the Executive Committee will make its recommendation to the General Assembly in 2005. The closing date for bids is 15 August 2003.
We are a part of a w orldwide community of psychiatrists with our heart and soul in providing improved care for patients. The WPA has produced a statement drawing the attention of governments to the adverse consequences for mental health of any war and in particular a war in Iraq.

The W PA statement on Iraq was preceded by a similar statement about the mental health consequences of the Palestinian- Israeli conflict.

We must, I believe, strengthen, not undermine, existing international organisations which we need - or will need to reinvent. It would be good if members of the College can come to the World Congress in Cairo on 10-15 September 2005 to celebrate ' 5000 years of Science and Care'.

\section{News and notes}

For contributions to this column, please contact Brian Martindale FRCPsych, Psychotherapy Department, John Conolly Wing, Ealing, Hammersmith and Fulham Mental Health NHS Trust, Uxbridge Road, Hanwell UB1 3EU, UK, email brian.martindale@wlmht.nhs.uk

\section{European psychiatric organisations}

D uring recent years a number of Europe-wide psychiatric organisations have developed, each with their separate and overlapping goals. These organisations and their programmes will be fully described over time in more detail in International Psychiatry. As 'globalisation' and the influence of the European U nion continue to increase, there are increasing consequences in Europe for psychiatry and the broader field of mental health (BM J, 2002, vol. 324, pp. 991-992):

o There is now greater movement of psychiatrists between countries, both to take up employment and to attend conferences and other meetings.

o The European Union is introducing public health policies that include actions in mental health.

o The European U nion has made available funds for trans-national research.

o The WHO is adopting an increased commitment to the mental health programme in all regions.

o Psychiatry in Eastern and Central European countries has been undergo ing profound reform.

In July 2001, leaders of the major European psychiatric organisations met formally for the first time in London. The success of that meeting stimulated further meetings in 2002 in Stockholm, Yokohama and Copenhagen (twice). The outcome has been a clear intention to define areas of mutual concern and cooperation through task groups in order to effect a strengthening of psychiatry in Europe.

Already a w orking party has been set up with the aim of achieving pan-European agreement on principles and methods of approval for continuing medical education (CME) for psychiatrists. A meeting is planned for 19 June 2003 in Vienna before the World Psychiatric Association's thematic meeting. Leaders will discuss both CME and recruitment to the profession. A further meeting will take place during the Association of European Psychiatrists meeting in Geneva in April 2004.

The organisations involved in this new phase of European cooperation are the UEMS (European U nion of Medical Specialists Section and Board of Psychiatry), the AEP (Association of European Psychiatrists), the WPA (World Psychiatric Association) European Region and the W HO Regional O fice for Europe.

\section{The WPA is looking for Permanent Secretariat facilities}

The World Psychiatric Association (WPA) wishes to establish a Permanent Secretariat and is looking for a host organisation that can provide stable, economic and independent facilities with a minimum of 800 square feet and an appropriate ambience. If you feel that your organisation/ institution would be interested in investigating this possibility further, with its enormous potential for mutual benefits, contact Brian Martindale, c/o Marion Palmer-Jones at the Royal College of Psychiatrists, 17 Belgrave Square, London SW IX 8PG, UK, for further information. Preliminary bids must be submitted by 15 August 2003.

\section{RCPsychNSO fellowship}

Voluntary Service 0 verseas (VSO ) enables skilled and professional volunteers to share their expertise in many of the world's poorest countries. W ith 40 years' experience, VSO passionately believes that such individuals can make a real difference in tackling disadvantage.

VSO and the Royal College of Psychiatrists are undertaking a jo int venture for UK specialist registrars already
The VSO fellowship scheme has been developed by the Board of International Affairs at the College and is coordinated by a small subgroup. 